ESAIM: PROCEEDINGS, December 2003, Vol. 13, I

J.P. Penot, Editor

DOI: $10.1051 /$ proc/02000

\title{
PREFACE
}

\section{J.P. PENOT}

This volume contains the plenary lectures presented during the meeting of the MODE group of SMAI. The activity of the group is centered around optimization theory and practice, discrete mathematics, game theory, mathematical modeling in economics, finance and social sciences, nonlinear analysis, optimal control. The lectures presented during the industrial session and the short communications are not included in this volume. The editor would like to thank again the Scientific Committee, the Local Organizing Committee (and especially its Chairman Serge Gautier), Sponsors (Artelys, the Council of Pyrnes Atlantiques, the Council of the Aquitaine Region, the Council of the township of Pau, Electricit de France, the SMAI, Total-Fina- Elf, the University of Pau) and Exhibitors (Springer, World Scientific), which supported the organization of the conference and, of course, all participants. 